\title{
Glyco-Tandem Mass Tag
}

National Cancer Institute

\section{Source}

National Cancer Institute. Glyco-Tandem Mass Tag. NCI Thesaurus. Code C161871.

A tandem mass tag reagent preparation bearing a reactive group that enables labeling and quantitative profiling of glycopeptides, carbohydrates, steroids, or oxidized proteins. 